\section{Revista Thema}

V.18 Especial 2020

p.184-203
DOI: http://dx.doi.org/10.15536/thema.V18.Especial.2020.184-203.1850

ISSN: 2177-2894 (online)
CIÊNCIAS HUMANAS

\section{Ciências na pandemia: uma proposta} pedagógica que envolve interdisciplinaridade e contextualização

Sciences in the pandemic: a pedagogical proposal that involves interdisciplinarity and contextualization

Janainne Nunes Alves ${ }^{1}$, Bruno Lopes de Faria ${ }^{2}$, Paulo Giovane Aparecido Lemos ${ }^{3}$, Claudiane Moreira Costa ${ }^{4}$, Cléber Silva e Silva ${ }^{5}$, Ramony Maria da Silva Reis Oliveira ${ }^{6}$

\title{
RESUMO
}

O fechamento de escolas no Brasil durante a pandemia da COVID-19 deixou milhões de estudantes e professores dependentes da educação mediada pelas tecnologias. Nesse sentido, esse estudo discute a interdisciplinaridade e a mediação tecnológica como alternativas ao processo educacional no contexto emergencial da pandemia. Nossa proposta se desenvolve como aporte teórico metodológico ao ensino remoto e relaciona as unidades curriculares de Matemática, Química e Informática a temas centrais para o diálogo e construção contextualizada do conhecimento. A pesquisa foi desenvolvida em meados do primeiro semestre de 2020 a partir de análises qualitativas e exploratórias associadas ao projeto de ensino do IFNMG/Diamantina. Os conteúdos foram disponibilizados aos estudantes na plataforma Google Classroom e elucidados como informações relevantes para compreensão das características e formas de propagação do coronavírus. A plataforma e a metodologia adotadas permitiram uma boa interação entre os sujeitos, bem como proporcionou que os estudantes adquirissem competências para interpretar a complexidade do momento atual, por meio do desenvolvimento de conhecimentos indispensáveis à formação de opinião e enfrentamento do vírus.

Palavras-chave: Prática pedagógica; COVID-19; educação mediada por tecnologias.

\footnotetext{
${ }^{1}$ Instituto Federal de Educação, Ciência e Tecnologia do Norte de Minas Gerais - IFNMG, campus Diamantina, Diamantina/MG - Brasil. E-mail: janainne.alves@ifnmg.edu.br

${ }^{2}$ Idem. E-mail: bruno.lopes@ifnmg.edu.br

${ }^{3}$ Idem. E-mail: paulo.lemos@ifnmg.edu.br

${ }^{4}$ Idem. E-mail: claudiane.costa@ifnmg.edu.br

${ }^{5}$ Instituto Federal de Educação, Ciência e Tecnologia do Pará - IFPA, Belém/PA - Brasil. Idem. E-mail: cleber.silva@ifpa.edu.br

${ }^{6}$ Instituto Federal de Educação, Ciência e Tecnologia do Norte de Minas Gerais - IFNMG, campus Diamantina, Diamantina/MG - Brasil. E-mail: ramony.oliveira@ifnmg.edu.br
} 


\section{ABSTRACT}

The closure of schools in Brazil during the COVID-19 pandemic left millions of students and teachers dependent on technology-mediated education. In this sense, this study discusses interdisciplinarity and technological mediation as alternatives to the educational process in the emergency context of the pandemic. Our proposal is developed as a methodological theoretical contribution to remote teaching and relates the Mathematics, Chemistry and Informatics courses to central themes for dialogue and contextualized construction of knowledge. The research was developed in the middle of the first semester of 2020 from qualitative and exploratory analyzes associated with the IFNMG/Diamantina teaching project. The contents were made available to students on the Google Classroom platform and elucidated as relevant information for understanding the characteristics and ways of spreading the coronavirus. The adopted platform and methodology allowed a good interaction between the subjects, as well as allowing students to acquire skills to interpret the complexity of the current moment, through the development of knowledge that is indispensable for forming opinions and facing the virus.

Keywords: Pedagogical practice; COVID-19; technology-mediated education.

\section{INTRODUÇÃO}

Desde o registro dos primeiros casos de infecção pelo coronavírus, o contágio por COVID-19 entre os seres humanos se deu de maneira bastante rápida. Em poucas semanas a doença atingiu abrangência mundial e tem ocasionado problemas políticos, econômicos e sociais de grandes proporções. (FRANCO et al., 2020).

No Brasil, a pandemia por COVID-19 apresenta um número crescente de mortes com ascendência da curva epidemiológica e o controle da doença tem se apresentado como um grande desafio. Uma realidade agravada pela grande desigualdade social e demográfica, com populações vivendo em condições precárias de habitação e saneamento, sem acesso constante à água, em situação de aglomeração e alta prevalência de doenças crônicas. Fatores que associados ao conhecimento insuficiente acerca das características do vírus e suas formas de transmissão, geram incertezas quanto à escolha nas estratégias de enfrentamento da doença. (BARRETO, 2020).

Diante disso, estados e municípios vêm adotando, desde meados de março de 2020, políticas de distanciamento e isolamento social como táticas para reduzir as taxas de contágio pela população. Situação que mudou drasticamente o cotidiano dos brasileiros sob os mais diferentes âmbitos. No que diz respeito ao cenário educacional, o Ministério da Educação (MEC), em atendimento à solicitação da Associação Brasileira de Mantenedoras de Ensino Superior (ABMES), às orientações do Conselho Nacional de Educação (CNE) e recomendações da Organização Mundial da Saúde (OMS), publicou a portaria número 343 de 17 de março de 2020. Documento que flexibilizou em caráter excepcional a substituição das disciplinas presenciais, em andamento, por aulas que utilizem meios e tecnologias de informação e comunicação inicialmente por 30 dias, que vêm sendo prorrogados desde então. 
À vista das recomendações do MEC, professores e instituições de ensino buscam mecanismos que promovam o ensino e a aprendizagem apesar do distanciamento social. Neste seguimento, as tecnologias digitais vêm ganhando repercussão como ambientes virtuais nos processos educacionais e passaram a ser vislumbradas como possíveis alternativas pelas instituições de ensino de todo país.

Nesse sentido, e considerando as fragilidades sociais e econômicas impostas a inúmeros estudantes, particularmente os da rede pública de educação, o Instituto Federal do Norte de Minas Gerais (IFNMG) iniciou processos internos de pesquisa para levantar dados sobre o acesso dos estudantes à internet e dispositivos tecnológicos. Esta pesquisa se respalda na missão da rede federal de educação que, como instituições públicas, buscam democratizar o acesso à educação, reduzir a desigualdade social, assegurando inclusive a igualdade de oportunidades e permanência dos discentes em situações de vulnerabilidade. (BRASIL, 2010). Assim, como a referida pesquisa encontra-se em andamento e, portanto, com insuficiência de resultados que indiquem a viabilidade da implementação de propostas educacionais a distância de amplo alcance entre os estudantes do IFNMG, não serão pormenorizadas questões sobre a efetivação da educação a distância (EAD) neste artigo.

Destaca-se que a EAD abarca conceitos e sentidos importantes em aspectos amplos e atinge perfis estudantis específicos que necessitam da flexibilização no tempo e espaço, propostas por essa modalidade. Dessa maneira, não nos manifestamos contrários a EAD, mas, reiteramos que o escopo desse trabalho se limita a uma abordagem interdisciplinar por meio da articulação entre ciências da natureza, matemática e suas tecnologias e informática (pertencentes a grande área "Ciências Exatas e da Terra") desenvolvida sob o contexto do isolamento social imposto pela COVID-19.

Em síntese, esse estudo tem por objetivo apresentar uma proposta didáticopedagógica executada nos cursos de Ensino Médio Integrado à Educação Profissional Tecnológica - EMIEPT do IFNMG/Diamantina por meio do ensino remoto ${ }^{7}$ e aplicação de tecnologias mediadoras no processo educativo. Nesse âmbito, foram vislumbradas reflexões sobre interdisciplinaridade e contextualização de conceitos abarcados em Matemática, Química e Informática na unidade curricular (UC) "Ciências na Pandemia", que relaciona conteúdos didáticos e concepções importantes para compreensão das características e formas de propagação do coronavírus. Recursos implementados como forma de enfrentamento da crise mundial instaurada pela pandemia.

\section{INTERDISCIPLINARIDADE, CONTEXTUALIZAÇÃO E O CURRÍCULO DO IFNMG/DIAMANTINA}

Os Institutos Federais de Educação Profissional e Tecnológica compõem uma rede educacional que tem como princípios a promoção e o desenvolvimento da formação

\footnotetext{
${ }^{7}$ O Plano de Trabalho para a oferta de Unidades Curriculares, de forma remota, previstas no Núcleo Integrador, que compõe a organização curricular dos Cursos Técnicos Integrados ao Ensino Médio do IFNMG - Campus Diamantina foi aprovado, ad referendum, através da PORTARIA REITOR №221/2020.
} 


\section{Edição Especial COVID-19}

dos educandos pela integração entre os currículos do Núcleo Técnico (relativos à área profissional) e do Núcleo Básico (componentes curriculares da Educação Básica/Nível Médio). Essas instituições têm a interdisciplinaridade e a politecnia como fundamentos curriculares dos cursos EMIEPT e detém autonomia na construção curricular. (BRASIL, 1996; BRASIL, 2012; BRASIL,2017; CONIF/FDE, 2018).

A autonomia, assim como, os princípios dos Institutos permitem uma organização disciplinar flexível que considera fundamentos científicos, sociais, organizacionais, econômicos, políticos, culturais, ambientais, estéticos e éticos como alicerce para as tecnologias. (BRASIL, 1996; BRASIL, 2012; BRASIL,2017). Na disposição da matriz da Educação Profissional e Tecnológica (EPT) a ciência, a tecnologia e a sociedade integram eixos estruturantes que se articulam com vistas a uma formação que pressupõe a compreensão de concepções subjacentes, tais como, a sociedade, o homem, o trabalho, a ciência e a técnica, imersas no contexto escolar. (RAMOS, 2008; ARAÚJO E SILVA, 2012).

Nesse sentido, os princípios do EMIEPT se estruturam a partir da tríade "trabalho, ciência e cultura", cuja amplitude de objetivos curriculares têm como referências: (i) o questionamento das formas herdadas de estudar e atuar sobre a natureza; (ii) a contextualização, pela escola, dos conhecimentos em relação às necessidades sociais; (iii) a integração entre conhecimento teórico e conhecimento prático; (iv) a redução da segmentação do conhecimento; e, (v) a promoção da autenticidade da democracia do conhecimento científico e tecnológico. (RAMOS, 2008; ARAÚJO E SILVA, 2012).

Tais concepções denotam que a EPT se encontra arraigada pela interdisciplinaridade e contextualização dos fenômenos. Inferências que permitem abordagens educacionais que têm a possibilidade de promover discussões e compreensões amplas dos conteúdos, por meio da articulação disciplinar.

A interdisciplinaridade pressupõe a compreensão dos problemas conforme seu aspecto multifacetado, fatores que são sempre apresentados e discutidos no que diz respeito às práticas didático-pedagógicas contemporâneas. Corporificando, assim, uma forma de pensar e produzir conhecimento advinda da emergência em inovar o pensar e o fazer ciência. Orientando-nos a práticas pedagógicas com vistas à realidade, estimulando nesse sentido, a coexistência de sujeitos distintos, com seus saberes em áreas diversas a atuarem conjuntamente sobre as circunstâncias cotidianas. (RAMOS, 2003; DOS SANTOS, 2018; LOUREIRO et al., 2019).

Nessa perspectiva, a construção do conhecimento, no contexto da realidade, vislumbra a promoção do conhecimento efetivo, com significado próprio, alcançado mediante a articulação entre os conceitos que também se fazem presentes no dia a dia dos estudantes. (BRASIL, 2000). Reflexões acerca das diretrizes educacionais brasileiras, também, apontam ao desenvolvimento de processos que fomentem a formação em sentido profundo e abrangente, fortalecendo as bases para interpretação dos fatos naturais e a compreensão de situações/procedimentos diários. (ALVES, et al., 2018). Como nos apresenta Kuhn: 
[...] os cientistas nunca aprendem conceitos, leis e teorias de uma forma abstrata e isoladamente. Em lugar disso, esses instrumentos intelectuais são desde o início, encontrados numa unidade histórica e pedagogicamente anterior, onde são apresentados juntamente com suas aplicações a uma determinada gama concreta de fenômenos naturais; sem elas, não poderia nem mesmo candidatar-se à aceitação científica. (KUHN, 1998, p.71).

Ainda sob a concepção da autonomia curricular dos Institutos, e sob os pressupostos da interdisciplinaridade, como proposta de contextualização dos conteúdos disciplinares, o IFNMG campus Diamantina se propõe a ofertar uma formação singular aos sujeitos através da organização dos cursos EMIEPT a partir de três núcleos: o Núcleo Básico, o Núcleo Tecnológico e o Núcleo Integrador (Parte diversificada).

O Núcleo Básico integra o espaço destinado à oferta de disciplinas relativas às áreas de conhecimento da formação básica. O Núcleo Tecnológico destina-se às disciplinas relacionados ao perfil profissional do egresso e sua formação técnica. $E$, por último, o Núcleo Integrador, que constitui um espaço ao qual se destinam as unidades curriculares que abrangem conhecimentos e habilidades inerentes à educação básica e técnica, que possuem maior área de integração com as demais disciplinas do curso em relação ao perfil do egresso, bem como pela integração entre os Núcleos Tecnológico e Básico. (IFNMG, 2017).

Um formato curricular que corrobora com a prática interdisciplinar de Santomé (1998), a qual defende a construção de unidades didáticas integradas, desenvolvidas através do trabalho coletivo e incorporação de determinado número de disciplinas, ou mesmo áreas do conhecimento. Segundo Santomé (1998) tais unidades são elaboradas em torno de uma situação-problema e exigem, portanto, a contribuição de diferentes saberes para sua compreensão. (LAVAQUI; BATISTA, 2007).

Essa disposição curricular permite, por meio do Núcleo Integrador, a implementação de unidades curriculares dinâmicas, elaboradas continuamente por professores e estudantes, com o suporte do Núcleo Pedagógico institucional. Consolidando-se como um espaço propício à contextualização e interdisciplinaridade. É imperioso destacar que as unidades curriculares do Núcleo Integrador não se confundem com as disciplinas convencionais (Núcleo Básico e Técnico), pois têm características próprias para sua oferta. Entretanto, esses Núcleos articulam-se de forma que, com a extensão e a pesquisa, complementam-se na promoção de um EMIEPT que não separa cultura, ciência e trabalho. (IFNMG, 2020).

É importante ressaltar, que os estudantes escolhem, com a ajuda de um mediador ${ }^{8}$, as unidades do Núcleo integrador que cursarão, independe do eixo tecnológico do curso. Um modelo que converge em uma organização singular e dinâmica dos currículos, uma vez que as unidades são formuladas continuamente e apresentadas aos

\footnotetext{
${ }^{8} \mathrm{O}$ mediador é a figura (servidor do IFNMG) que acompanha o estudante ao longo do processo formativo, ajudando-o a realizar a escolha de unidades curriculares do Núcleo Integrador a partir dos objetivos traçados na etapa de formação.
} 
estudantes a partir da discussão de assuntos emergentes na sociedade com a articulação das áreas do conhecimento.

\section{METODOLOGIA}

O presente estudo possui cunho qualitativo e exploratório (RICHARDSON, 1999; FIGUEIREDO, 2008) e foi realizado sob as perspectivas da matriz do EMIEPT do campus Diamantina e do ensino mediado por tecnologias na conjectura da pandemia ocasionada pela COVID-19, bem como, pela necessidade de aportes metodológicos interdisciplinares impostas ao ensino médio contemporâneo. Nesse sentido, a UC "Ciências na Pandemia" foi desenvolvida como como recurso a um processo educativo harmônico, pautado na interlocução entre os universos escolar e social.

A oferta dessa unidade no Núcleo Integrador do IFNMG/Diamantina ocorreu na metodologia não presencial mediada por tecnologias aos cursos do EMIEPT em Teatro, Informática e Meio Ambiente, inicialmente, em caráter excepcional, pelo período de isolamento social, em meados do primeiro semestre de 2020. Dada a incompreensão momentânea acerca da infraestrutura tecnológica nas residências dos estudantes.

Sua instrumentalização se deu por meio da aprovação ad referendum da portaria 221/2020 do IFNMG, que autorizou a oferta remota do Núcleo Integrador, mediante às orientações da portaria 343 de 17 de março de 2020 do MEC.

Essa UC foi estruturada segundo os princípios da interdisciplinaridade, por meio da articulação entre as disciplinas de Matemática, Química (integrantes das "Ciências da Natureza, Matemática e suas Tecnologias", referenciadas nas Orientações Educacionais complementares aos Parâmetros Curriculares Nacionais) e Informática como disciplina do Núcleo tecnológico. (BRASIL, 2002).

Perante os desígnios da unidade, encontra-se a abordagem científica como artifício ao enfrentamento da COVID-19, que oportuniza aos estudantes subsídios para tomada de decisões diante da realidade advinda da pandemia no Brasil. Uma vez que nos encontramos em um cenário que as atitudes, os juízos ou os valores entrelaçam-se e a disseminação de informações que propiciem a construção de conhecimentos fundamentais ao enfrentamento da COVID-19 é tida como essencial.

A proposta foi suportada por tecnologias digitais, como mediadores no processo de ensino e aprendizagem, aqui representadas pelo Google Classroom ${ }^{9}$. Nesse aspecto, o Youtube também foi utilizado como tecnologia síncrona/assíncrona e plataforma de suporte midiático que permitiu a interação entre professores e estudantes da unidade curricular.

\footnotetext{
${ }^{9}$ A plataforma utilizada para mediação do processo ensino/aprendizagem foi o Google Classroom, por possibilitar interações síncronas e assíncronas na mediação pedagógica, bem como amplas potencialidades pedagógicas para o ensino remoto. Trata-se de uma plataforma gratuita muito utilizada para no ensino a distância, com acesso livre a outros acessórios do Google como o Google Meet e a agenda. Recursos aliados ao fácil acesso, já que não há necessidade de realizar nenhuma instalação no computador. (GOOGLE CLASSROOM, 2020).
} 


\section{RESULTADOS E DISCUSSÃO}

A interdisciplinaridade propõe que as relações entre a ciência, a tecnologia e a sociedade ocorram pela convergência entre as diferentes áreas do conhecimento, de forma a permitir discussões e correlações complexas pela diversidade de enfoques dada a uma mesma situação. Compreende-se dessa maneira que a UC "Ciências na Pandemia" abarca os princípios da EPT. (RAMOS, 2008). Que também são convergentes com as concepções da didática integrada de Santomé (1998), a qual prevê possibilidades de análises e discussões mais ricas pela abordagem de uma situação- problema e estabelecimento de vínculos entre as disciplinas. (LAVAQUI; BATISTA, 2007).

Logo, subtende-se que educar compreende preparar os estudantes para a vida em espectro amplo. Fator que foi observado nesse estudo e implementado no sentido de formar e disseminar conhecimento como formas de prevenir e reduzir a propagação acelerada do vírus SARS-CoV-2.

Diante dessa abordagem pedagógica agregadora e que permeia discussões e reflexões sobre os fenômenos naturais e científicos, apresentamos o processo de articulação entre as disciplinas de Matemática, Química e Informática (figura 1), bem como os conteúdos programáticos a elas vinculados sob a perspectiva da compreensão de concepções relativas ao evento da pandemia.

Figura 1 - Análise da Pandemia por COVID-19 a partir das disciplinas de Matemática, Química e Informática.

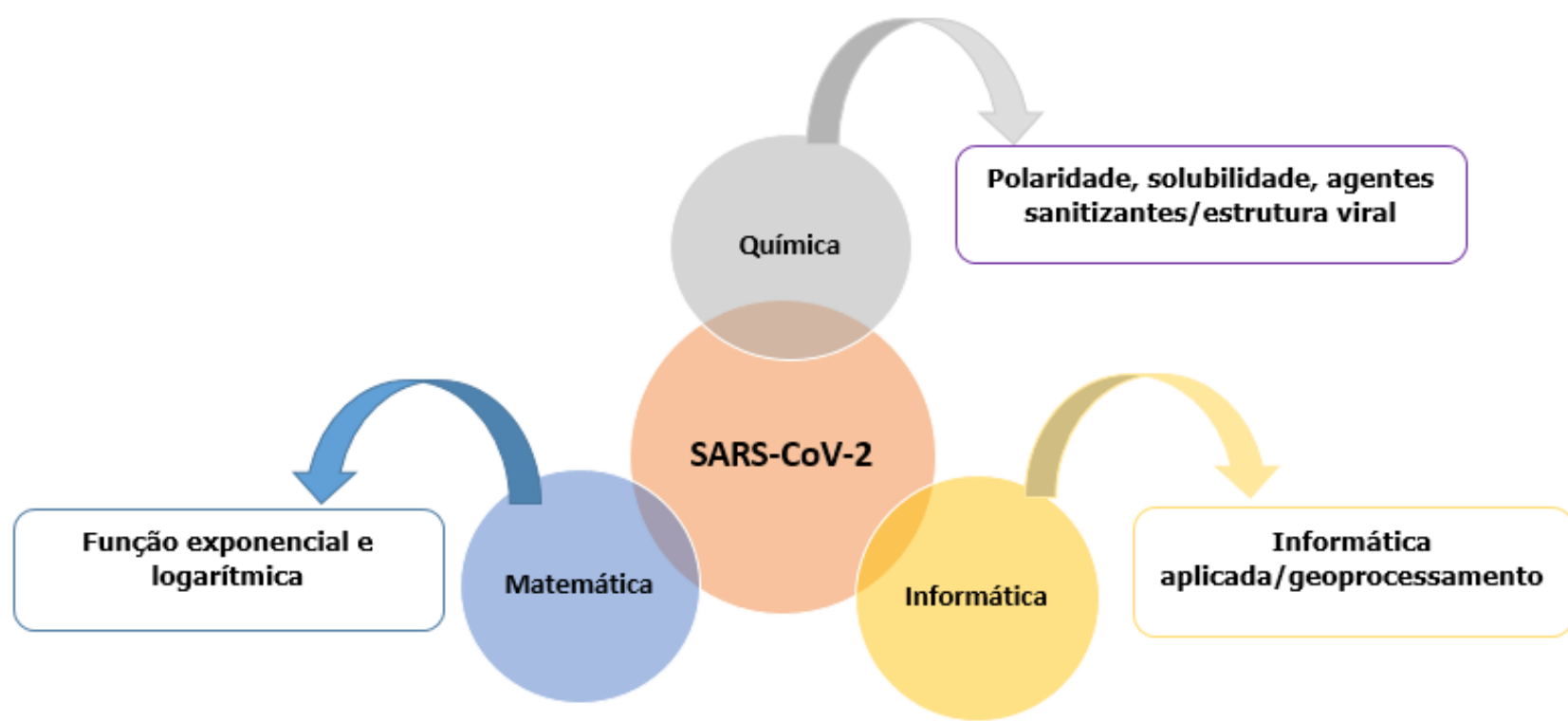

Fonte: Elaborado pelos autores.

No sentido de ampliar as percepções acerca dos processos relacionados às discussões da temática (pandemia), os conteúdos abordados pelos componentes da UC "Ciências na Pandemia" foram correlacionados às habilidades a serem desenvolvidas pelos estudantes e explicitados no quadro 1. 
Quadro 1 - Abordagem curricular/descrição das habilidades correlacionadas.

\begin{tabular}{|l|l|l|}
\hline CONTEÚDOS/CONCEITOS & CONTEXTO & HABILIDADES \\
\hline $\begin{array}{l}\text { Polaridade, solubilidade, forças } \\
\text { intermoleculares }\end{array}$ & $\begin{array}{l}\text { Estrutura viral do coronavírus } \\
\text { e ação dos sanitizantes na } \\
\text { minimização das taxas de } \\
\text { contágio. }\end{array}$ & $\begin{array}{l}\text { Construir visões mais complexas } \\
\text { sobre a natureza científica. } \\
\text { Compreender a importância da } \\
\text { ciência no mundo moderno } \\
\text { frente ao estudo do vírus. }\end{array}$ \\
\hline $\begin{array}{l}\text { Informática aplicada, análise } \\
\text { espacial, informações } \\
\text { georreferenciadas }\end{array}$ & $\begin{array}{l}\text { Mapeamento da disseminação } \\
\text { do coronavírus no contexto } \\
\text { local. }\end{array}$ & $\begin{array}{l}\text { Compreender as funções do } \\
\text { geoprocessamento no estudo de } \\
\text { epidemias através da relação }\end{array}$ \\
\hline $\begin{array}{l}\text { Função expontre o extermínio de outras } \\
\text { aspectos evolutivos do contágio }\end{array}$ & $\begin{array}{l}\text { podelagem matemática dos } \\
\text { dados e análise dos } \\
\text { resultados referentes à } \\
\text { propagação viral com e sem a } \\
\text { adoção de medidas } \\
\text { protetivas. }\end{array}$ & $\begin{array}{l}\text { e sua importância para análise } \\
\text { do cenário atual. }\end{array}$ \\
\hline $\begin{array}{l}\text { Compreender o processo } \\
\text { histórico, a evolução dos dados } \\
\text { referentes à COVID-19 no Brasil. } \\
\text { Capacidade de realizar uma } \\
\text { análise pormenorizada das } \\
\text { práticas de enfrentamento } \\
\text { adotadas. }\end{array}$
\end{tabular}

Fonte: Elaborado pelos autores.

A sequência metodológica adotada (figura 02) nas atividades foi idealizada com o anseio de suscitar maior interação e construção colaborativa do ensino e aprendizagem, que foi suportado por momentos síncronos e assíncronos de reflexão e discussão. Essa abordagem buscou auxiliar não só a compreensão dos fatos/fenômenos da pandemia pela integração e relação com os conteúdos programáticos do ensino médio integrado, como também evidenciar uma visão sistêmica e holística dos fatos. Entendimento que corrobora com os preceitos de Kuhn, pois, nos remete a uma aprendizagem conectada a uma gama concreta de fenômenos. (KUHN, 1998).

Ainda sob o ponto de vista metodológico, este buscou envolver métodos e técnicas que têm o estudante como protagonista, de forma que desafiá-lo, instigá-lo e fazer com que ele encontrasse perguntas em vez de lhe dar respostas, consolidaram-se como maneiras de alcançar envolvimento, atenção e motivação. (TORI, 2015). 
Revista Thema

V.18 Especial 2020

\section{Edição Especial COVID-19}

Figura 2 - Abordagens metodológicas.

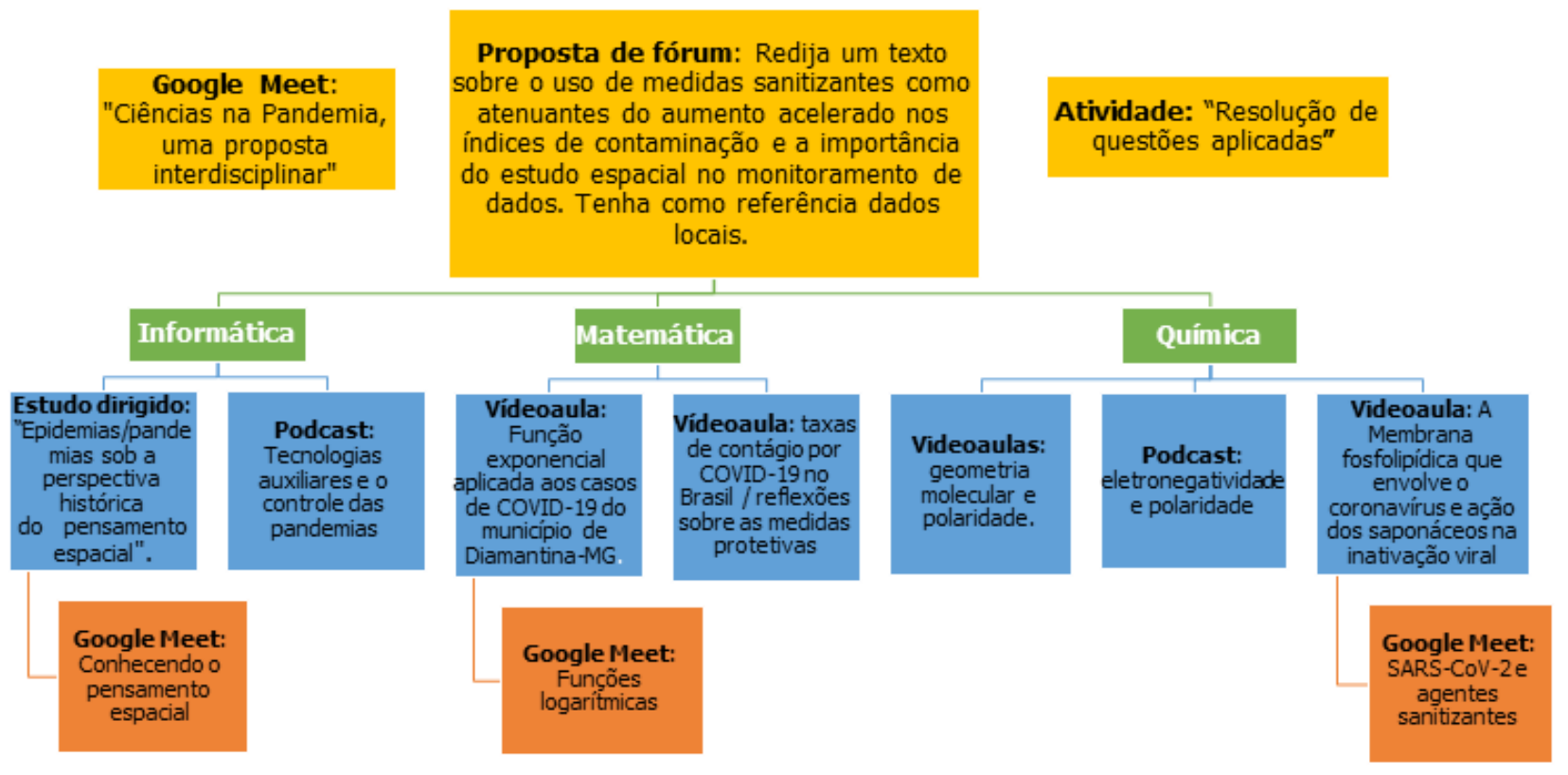

Fonte: Elaborado pelos autores.

Atentando-nos para o distanciamento físico professor/estudante no ensino remoto mediado por tecnologias, e para a maior autonomia dos estudantes, salienta-se que tais especificidades implicam em organizações didático-pedagógicas e metodológicas próprias (figura 2), uma vez que, nesse universo, o professor assume um papel distinto ao da prática convencional.

Este supervisionará e estimulará os estudantes, apoiando-os na construção do conhecimento, mas também formulará materiais didáticos que implementem mais que o conteúdo programático disponibilizado nos projetos políticos pedagógicos dos cursos, uma vez que, agora, estes materiais também devem ser sugestivos às novas modalidades de interação, como dimensão intrínseca ao processo remoto de ensinar e aprender.

Desse modo, vislumbra-se que os elementos expostos na figura 2, entre os quais citamos podcasts, videoaulas, fóruns e videoconferências, orientaram as relações e as formas pelas quais a gestão do ensino ocorreu, de forma a viabilizar o processo educacional e a integração entre professores e estudantes, potencializando o trabalho coletivo e as inter-relações entre os conhecimentos.

Nesse sentido, os momentos síncronos suportados pelo Google Meet se mostraram adequados para promoção de aproximações entre professor/estudante e professor/professor em situações distintas, como sanar dúvidas, realizar explicações 
mais densas, bem como apoiar o trabalho dos professores no desenvolvimento de uma visão coletiva da situação-problema, pressupostos da interdisciplinaridade. (SANTOMÉ, 1998). Todas as videoaulas foram produzidas pelos professores e postadas no Youtube em um canal institucional do IFNMG e o chat dessa plataforma se consolidou como mais uma via de integração e comunicação entre professores e estudantes.

Ainda, como forma de diversificar os estímulos no ambiente virtual de aprendizagem (Google Classroom), podcasts foram gravados e disponibilizados na sala virtual em formatos digitais e acesso online, o que permitiu seu armazenamento no computador, dispositivo móvel e/ou compartilhamento via internet pelos estudantes.

O fórum, um momento assíncrono (figura 2), incitou uma reflexão abrangente, o que propiciou uma boa articulação entre os conceitos abarcados na UC, por meio da ótica da interdisciplinaridade como instrumento direcionador de uma formação que dá suporte para compreensão em sentido pluralístico da temática (pandemia). Destacase ainda, que esse momento relacionou conhecimentos e conceitos científicos e tecnológicos aplicados a uma situação contemporânea como auxiliar na construção dos saberes. (RAMOS, 2008; SANTOMÉ, 1998; LAVAQUI; BATISTA, 2007).

\subsection{CONTEXTUALIZANDO O ENSINO DE MATEMÁTICA}

Iniciamos este tópico com a seguinte pergunta: quais são os conceitos matemáticos necessários para entender a evolução da pandemia por COVID-19?

A matemática como ciência pode auxiliar na compreensão das particularidades do fenômeno epidemiológico que vivenciamos no Brasil e no mundo pela sistematização e análise de dados. A observação do fluxo epidemiológico brasileiro, ocasionado pelo aumento no número de infectados e óbitos ocasionados pela COVID-19, nos levam a subentender que os mesmos se aproximam de um crescimento exponencial, além de indicar o avanço da doença em todos os estados do país, seja, nas capitais ou no interior.

Essas investigações proporcionadas pelo estudo matemático, nos colocam diante da necessidade de reflexão acerca das medidas de contenção e isolamento, bem como da adoção de medidas de higiene e limpeza pelas pessoas e comunidades, com o propósito de minimizar os impactos causados pela pandemia em suas diferentes faces, inclusive no ambiente escolar.

E são as funções logarítmicas e exponenciais, as progressões geométricas/aritméticas e as regressões lineares/não lineares, conteúdos programáticos do primeiro ano letivo do ensino médio, que permitem o acompanhamento evolutivo desses dados e têm se revelado fundamentais para a compreensão desse fenômeno que se apresenta por meio de grandezas que se multiplicam celeremente. Além de consubstanciarem uma representação visual mais clara dos dados. 
Na UC "Ciências na Pandemia", os estudantes se deparam com projeções do Ministério da saúde ${ }^{10}$ e realizaram cálculos e prospecções por meio de um paralelo com a investigação dos casos regionais (Diamantina/MG). Casos que foram projetados com o auxílio de técnicas de pensamento espacial corroboradas pelo estudo em informática aplicada.

A análise do quantitativo de casos (figura 3) ocorreu em consonância com discussões sobre as práticas de higiene e ação sanitizante observadas pelos estudantes em seu cotidiano e na comunidade, o que implicou em reflexões acerca do avanço da COVID19 em Diamantina/MG (região de aplicação da UC), visto que os dados do município (figura 3) indicam que o número de casos têm evoluído em progressão não exponencial, realidade que não acompanha a curva epidemiológica brasileira, fato que pode se relacionar às medidas de isolamento e às boas práticas higiênicas e de proteções adotadas pela comunidade até então.

Figura 3 - (A) Curva epidemiológica brasileira (óbitos confirmados);

(B) Curva epidemiológica brasileira (casos confirmados); e,

(C) Curva epidemiológica de Diamantina/MG (casos confirmados).

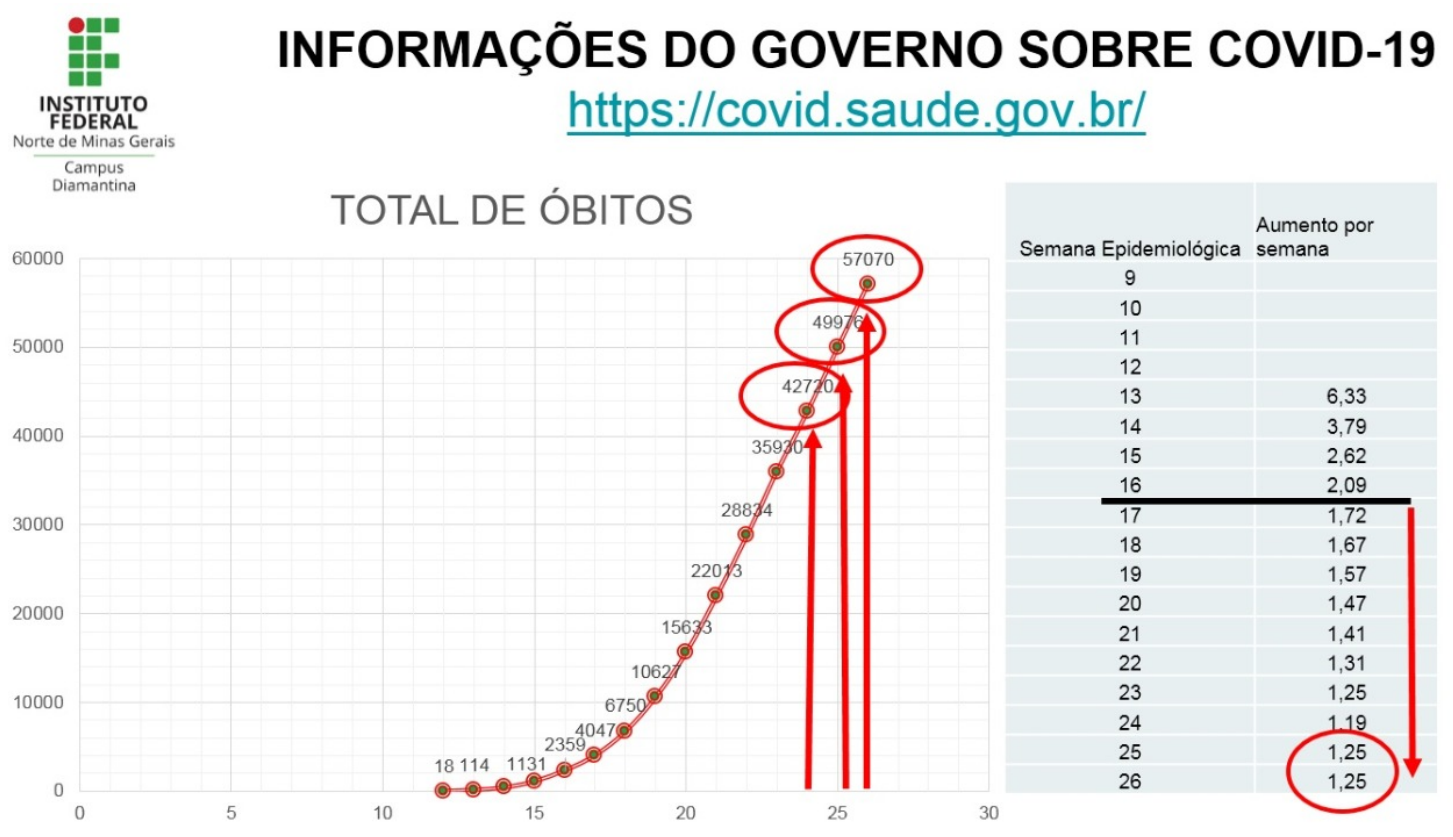

(A)

\footnotetext{
${ }_{10}$ Painel de casos de doença pelo Coronavírus 2019 (COVID-19) no Brasil. Disponível em:

<https://COVID.saude.gov.br/>. Acesso em: 30 jun. 2020.
} 


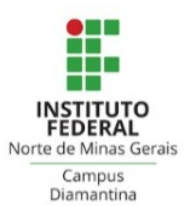

\section{INFORMAÇÕES DO GOVERNO SOBRE COVID-19 https://covid.saude.gov.br/}

TOTAL DE CASOS
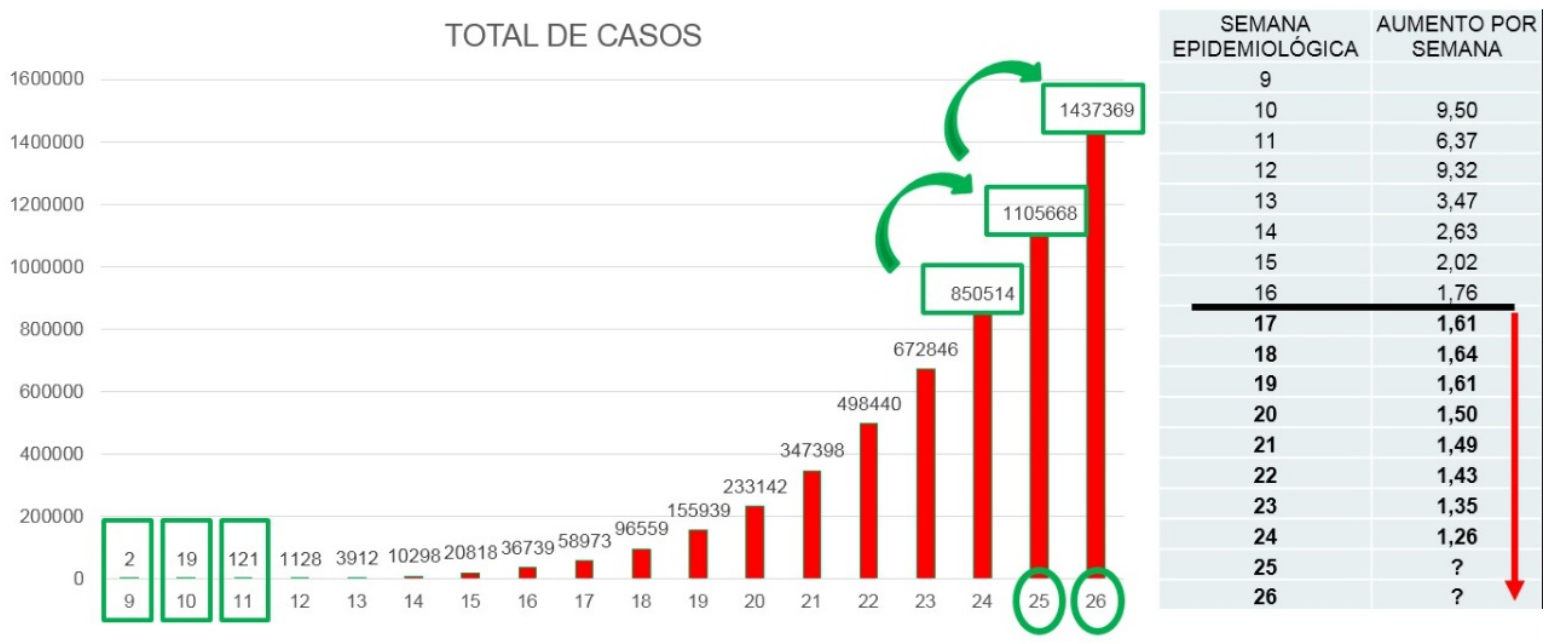

(B)

\section{INFORMAÇÕES DO MUNICÍPIO SOBRE COVID-19 https://diamantina.mg.gov.br/coronavirus/}

CASOS CONFIRMADOS NO MÊS DE JUNHO

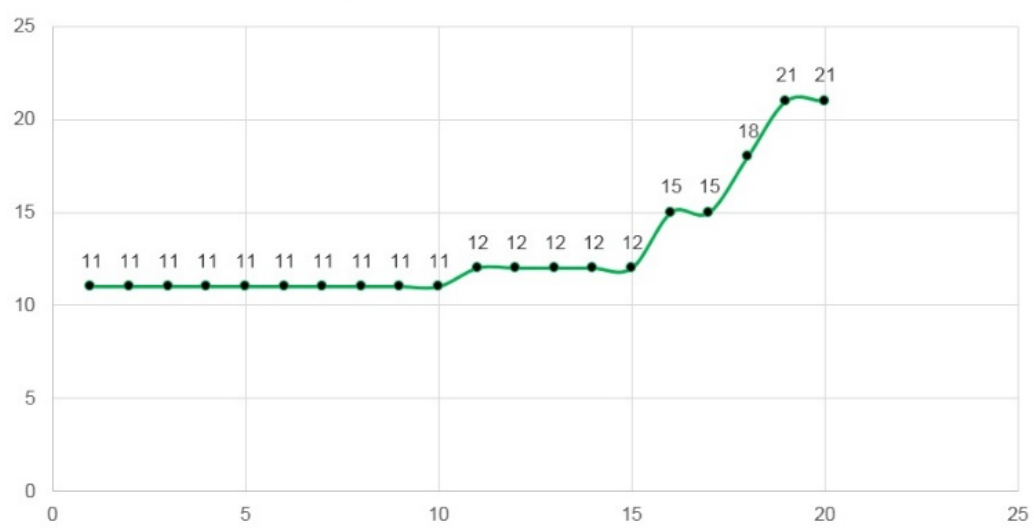

(C)

Fonte: Adaptado pelos autores dos sites disponíveis em: <https://COVID.saude.gov.br/> e <http://diamantina.mg.gov.br/noticias/categorias/coronavirus/>. Acesso em: 30 jun. 2020. 
Destaca-se que essas reflexões foram possíveis pela combinação das disciplinas (Matemática, Química e Informática) à luz de elementos presentes na realidade dos estudantes. Uma articulação que expandiu os significados e proporcionou aos estudantes competências para que estes interpretem a complexidade da atual situação pandêmica. (LAVAQUI; BATISTA, 2007; LOUREIRO et al., 2019). Prática pedagógica intrínseca à contextualização na EPT, tida como um eixo importante para dar significado ao conhecimento problematizado e apreendido pelo estudante, efetuado de maneira que ultrapasse a reprodução de exemplos, mas que amplie e abra possibilidades para o desenvolvimento de novas percepções. (RAMOS, 2003).

\subsection{CONTEXTUALIZANDO O ENSINO DE QUÍMICA}

O SARS-CoV-2, bem como outros tipos virais, apresenta um genoma constituído de uma ou várias moléculas de ácido nucleico (DNA ou RNA) e é revestido por um envoltório proteico formado por uma ou mais proteínas, além de uma espécie de envelope composto por uma bicamada fosfolipídica, como se observa na figura 4 . (OLIVEIRA; LUCAS; IQUIAPAZA, 2020).

Especificamente, os SARS-CoV-2, são vírus de RNA que possuem uma estratégia de replicação única, o que possibilita a variação de sua patogenicidade, com consequente facilidade de adaptação em diferentes ambientes. Quanto à origem, esse vírus é extremamente recente e provém de uma cepa nova, identificada no final do ano 2019, o que nos insere em um universo de incertezas e insuficiência de informações sobre seu comportamento no corpo humano. Assim, as medidas que vêm sendo implementadas no controle da pandemia visam à inativação viral como estratégia para impedir sua rápida transmissão pessoa/pessoa. (OLIVEIRA; LUCAS; IQUIAPAZA, 2020).

O processo de transmissibilidade entre humanos ocorre pela autoinoculação do vírus em membranas mucosas (nariz, olhos ou boca) e pelo contato com superfícies inanimadas contaminadas. O que implica em elevada eficácia na redução dos índices de contágio através da adoção maciça de higienização adequada das mãos, tida atualmente como uma medida de baixo custo e extremamente importante. (OLIVEIRA; LUCAS; IQUIAPAZA, 2020). Enquanto medida protetiva, a higienização das mãos pela fricção com água e sabão, expõe o RNA do vírus tornando-o inativo. Mas por que isso acontece?

Isso se deve à composição do envelope viral, visto que os fosfolipídios são moléculas que apresentam caráter anfifílico, ou seja, parte da molécula é hidrofóbica e parte hidrofílica. Característica também encontrada nas moléculas de sabão, semelhança que permite a interação com a camada externa do vírus.

Ao interagir com a camada fosfolipídica os sabões formam micelas que têm como propriedade a capacidade de encapsular materiais hidrofóbicos que são posteriormente solubilizados em água pelo ato de lavar as mãos. Ao permear a camada externa do vírus, seu material genético (RNA) fica exposto. E diante da sobrevida curta desse material, nos deparamos com a "inativação viral". 
É diante dos conceitos apresentados que propomos um ensino de química que dialoga com a realidade pela possibilidade de associação aos seguintes conteúdos programáticos do ensino médio: geometria molecular, polaridade, solubilidade e forças intermoleculares. Conteúdos que incorporados às trocas de experiências (estudante/estudante, estudante/professor) e interpretados conjuntamente a conceitos abordados em Matemática e Informática podem contribuir com a construção de uma visão multilateral de efeitos da pandemia. Consolidando-se assim como uma abordagem pedagógica alinhada aos preceitos de convergência e complementaridade, com vistas a uma compreensão complexa da realidade. Aspectos tidos como fundamentais na EPT como processo educacional emancipatório. (RAMOS, 2003; RAMOS, 2008).

Figura 4 - Conhecendo o SARS-CoV-2.

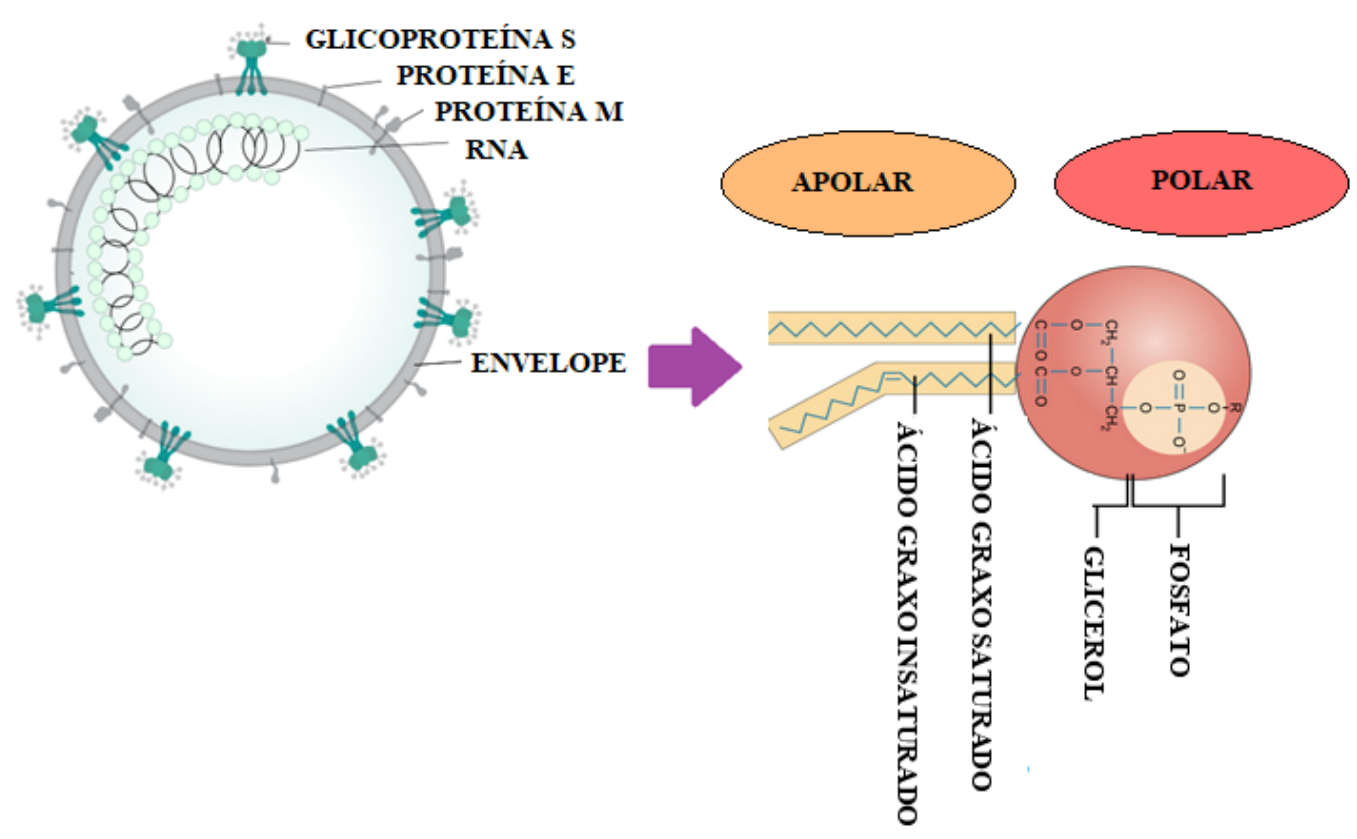

Fonte: Adaptado pelos autores, a partir de University of California. (DAVIS, 2020).

\subsection{CONTEXTUALIZANDO O ENSINO DE INFORMÁTICA}

O geoprocessamento abrange aspectos relacionados à informática, à geografia, à matemática e à lógica e constitui uma técnica que permite a representação de variações no espaço geográfico. As abordagens implementadas pelo geoprocessamento podem colaborar com a construção de processos de aprendizagem aplicados e contextualizados, pois as noções espaciais implementadas por essa técnica oferecem recursos para realização de estudos sistemáticos a partir da junção e sobreposição de informações cartográficas a dados ambientais, sociais, econômicos e culturais. (KERSKI, 2003).

É importante inferir que habilidades nessa área permitem inúmeras aplicações profissionais entre as quais se inserem: meio ambiente, informática, engenharia, 
urbanismo, transporte, arqueologia, turismo entre outras, de maneira que sua incorporação ao ensino no nível médio está intrinsecamente associada às diretrizes educacionais brasileiras e à EPT que orientam os educadores a práticas didáticopedagógicas que fomentem uma formação ampla e aplicada a diversas áreas como Química, Física, Matemática, entre outras. (RAMOS, 2003; ALVES; DE FARIA, 2020).

Em nossa UC, o enfoque inicial ocorreu através da apresentação do software (QGIS) ${ }^{11}$ aos estudantes. Em virtude desse software ter sido utilizado como recurso para levantamento e análise de dados regionais relativos às taxas de infectados e ao número de óbitos no perímetro de abrangência do IFNMG. Tais informações foram materializadas em mapas (figura 5) que ensejaram melhor entendimento da disseminação da doença por seu caráter visual. Nesse sentido, explicita-se que uma característica fundamental dos elementos tratados com geoprocessamento é a natureza dual da informação, ou seja, a informação é vinculada a uma localização (expressa como coordenadas em um mapa) e atributos descritivos (que podem ser representados em um banco de dados e/ou tabela). Fato que permitiu a associação dos dados ao contexto local e à realidade dos cursistas da UC.

Figura 5 - Boletim informativo Situação da COVID-19 no âmbito de atuação do IFNMG.

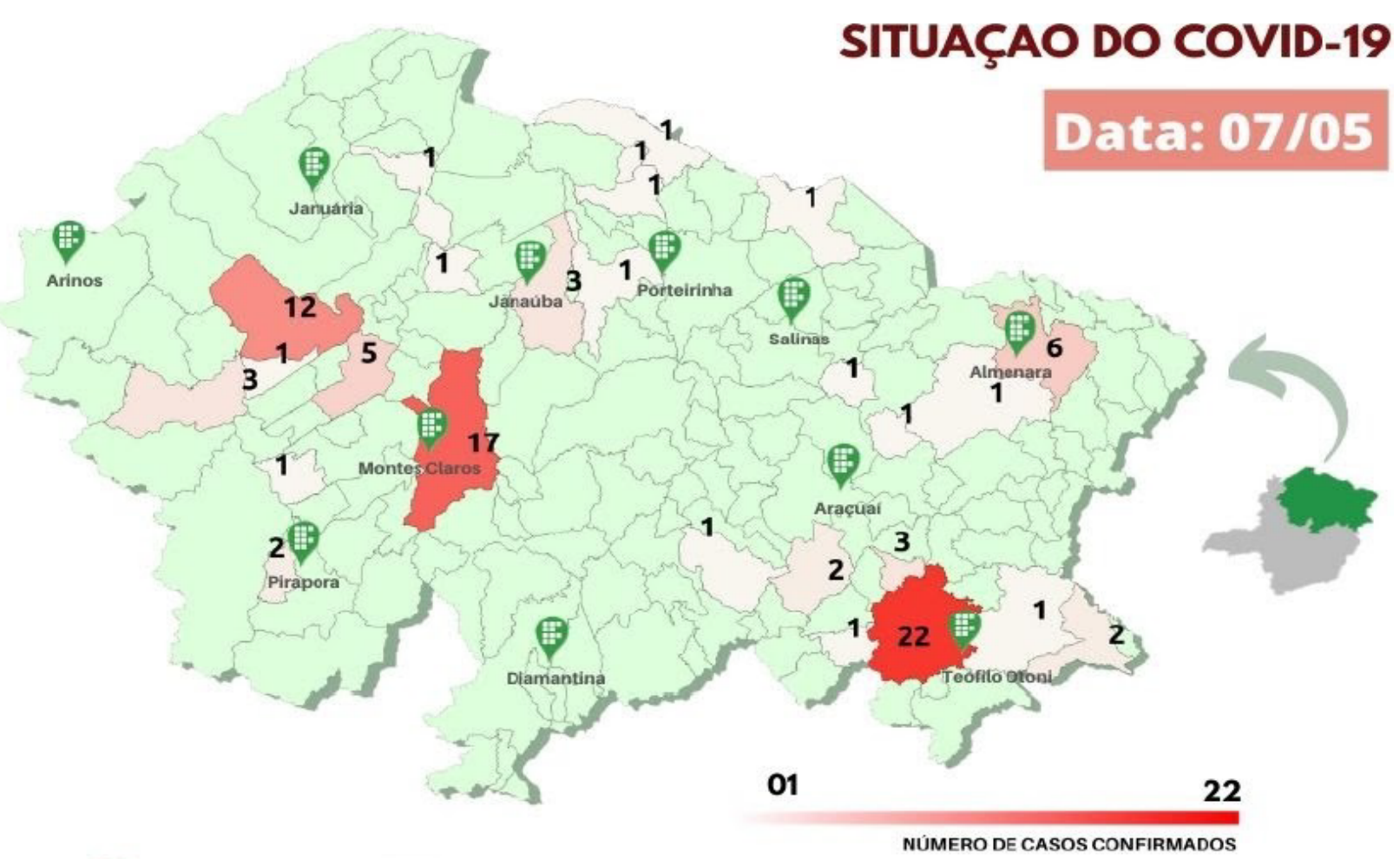

Fonte: Elaborado pelos autores.

\footnotetext{
${ }^{11}$ QGIS é um software livre com código-fonte aberto, multiplataforma de sistema de informação geográfica que permite a visualização, edição e análise de dados georreferenciados. (QGIS,2020).
} 
As reflexões e discussões com os estudantes foram direcionadas por meio do levantamento de dados oficiais disponibilizados pelas secretarias de saúde sobre os casos de COVID-19 na área de abrangência do IFNMG. Estes foram então analisados em função das medidas que vêm sendo tomadas pela comunidade em conjunto com as concepções apresentadas em Matemática e Química.

Por sua vez, a representação em mapas também foi apresentada aos estudantes como ferramenta visual auxiliar para antecipação de ações de enfrentamento da pandemia, visto que ela alerta a população a respeito do aumento de casos, bem como as cidades mais afetadas nas regiões de convivência da comunidade escolar. Contribuindo, portanto, com o tratamento matemático dos dados e conscientização da importância na adoção diária de ações sanitárias preventivas.

O aspecto histórico sob a ótica da tecnologia como auxiliar na luta da humanidade em situações epidêmicas/pandêmicas anteriores também foi abordado. Dinâmica desenvolvida por meio da apresentação de exemplos clássicos da análise espacial no enfrentamento de epidemias, como a de cólera que ocorreu em Londres em 1854. Uma ação que permitiu que os estudantes elaborassem um paralelo com a pandemia atual e sua relação com importância do mapeamento espacial. Tendo em vista que essas informações permitiram uma melhor compreensão sobre as formas de contaminação pela cólera, por meio do mapeamento dos doentes devido a sua associação aos poços de água da cidade, o que contribuiu significativamente com a erradicação da doença. (CARDOSO et al., 2020).

\section{CONSIDERAÇÕES FINAIS}

A declaração de situação pandêmica por COVID-19, com consequente fechamento de escolas e universidades em todo o mundo, implicou em uma interrupção abrupta das atividades escolares presenciais, o que tem tido reflexos no cotidiano de toda comunidade escolar e em toda a sociedade. Nos deparamos, então, com a inadequação da sala de aula tradicional diante da realidade em que nos encontramos e os processos de ensino e aprendizagem apropriaram-se do modelo remoto, mediado pelas tecnologias, em escalas não testadas e sem precedentes.

Sob essas prerrogativas apresentamos uma UC (Ciências na Pandemia) ofertada em caráter experimental através do ensino remoto, posto o cuidado do IFNMG, campus Diamantina/MG, com a expansão prudente da modalidade, que ocorre acompanhada por um criterioso diagnóstico e identificação de demandas iniciais, com o intuito de priorizar políticas institucionais nesse aspecto, caso sejam necessárias. Nessa perspectiva, a interdisciplinaridade se apresentou como recurso essencial e aportou uma interlocução entre as áreas do conhecimento (Matemática, Química e Informática), bem como enfatizou como a interdependência entre os conteúdos foi eficaz para o desenvolvimento de uma abordagem holística da temática (pandemia).

Quanto aos aspectos formativos enfatizados, observou-se que a Informática aplicada apresentou aos discentes a importância do pensamento espacial e uso de ferramentas 
aptas na busca de dados regionais sobre a COVID-19. A Química subsidiou a atuação de agentes sanitizantes como medida preventiva necessária e a Matemática uniu os conceitos pelo estudo dos dados espaciais, análise de probabilidades e estáticas do avanço do vírus diante de medidas de higiene e distanciamento. Fatos que levaram os estudantes a analisarem as informações e avaliarem como as projeções modeladas aproximaram/se aproximam de sua realidade.

A observação do processo avaliativo configurou-se como termômetro da aplicabilidade/viabilidade da UC. Esta foi elaborada coletivamente pelos professores e vislumbrou a resolução de questões aplicadas e o estímulo à análise da situação como um todo, bem como do pensamento complexo estimulado por meio de momentos síncronos e assíncronos de troca de informações. Nesse sentido, foi a boa interação e desempenho dos estudantes que identificaram o impacto positivo da unidade.

O Google Classroom trouxe um ambiente escolar dinâmico e permitiu o acesso a estímulos variados: vídeos, podcasts, textos, fóruns, momentos síncronos e momentos de encontro simultâneo, essenciais e adequados aos desdobramentos da disciplina, bem como da interatividade estudante/estudante, estudante/professor.

Finalizamos, destacando que essas possibilidades apresentadas aos professores e estudantes podem ser exploradas como didáticas/metodologias nesse momento de distanciamento e, principalmente, que permitem pela contextualização e interdisciplinaridade, uma atuação consciente e ativa dos estudantes na sociedade, ao mesmo tempo em que são abordados conteúdos programáticos do ensino médio.

\section{REFERÊNCIAS}

ALVES, Janainne Nunes et al. IFQuimical: uma proposta de mediação no processo ensino-aprendizagem de química. In: SIMPÓSIO BRASILEIRO DE INFORMÁTICA NA EDUCAÇÃO - SBIE, 29., 2018, Fortaleza. Anais... Fortaleza: SBC/UFC, 2018. p.61-70.

ALVES, Janainne Nunes; DE FARIA, Bruno Lopes. Design research e geotecnologias na educação básica sob a ótica da transdisciplinaridade. Research, Society and Development, v.9, n.2, p.e47921996(1-18), 2020.

ARAÚJO, Abelardo Bento; SILVA, Maria Aparecida da. Ciência, tecnologia e sociedade; trabalho e educação: possibilidades de integração no currículo da educação profissional tecnológica. Ensaio Pesquisa em Educação em Ciências, Belo Horizonte, v.14, n.1, p.99-112, 2012.

BARRETO, Mauricio Lima et al. O que é urgente e necessário para subsidiar as políticas de enfrentamento da pandemia de COVID-19 no Brasil? Revista Brasileira de Epidemiologia, v.23, Editorial, p.e200032(1-4), abr. 2020.

BRASIL. Lei de Diretrizes e Bases da Educação Nacional de 20 de dezembro de 1996. MEC. Brasília: DF. Disponível em: <http://www.planalto.gov.br/ccivil_03/leis/ 19394.htm>. Acesso em: 26 mai. 2020. 
BRASIL. Parâmetros Curriculares Nacionais para o Ensino Médio. 2000.

Disponível em: <http://portal.mec.gov.br/seb/arquivos/pdf/ciencian.pdf>. Acesso em: 24 mai. 2020.

BRASIL. MINISTÉRIO DA EDUCAÇÃO. Secretaria de Educação Média e Tecnológica. PCN+ Ensino Médio: orientações educacionais complementares aos Parâmetros Curriculares Nacionais - Ciências da Natureza, Matemática e suas Tecnologias. 2002. Disponível em: <http://portal.mec.gov.br/seb/arquivos/pdf/ CienciasNatureza.pdf>. Acesso em: 28 jul. 2020.

BRASIL. Decreto 7234 de 19 de julho de 2010. Dispõe sobre o Programa Nacional de Assistência Estudantil - PNAES. Presidência da república. Brasília/DF. Disponível em: < http://www.planalto.gov.br/ccivil_03/_ato2007-2010/2010/decreto/d7234.htm>. Acesso em: 20 jun. 2020.

BRASIL. Resolução № 6, de 20 de setembro de 2012. Define Diretrizes Curriculares Nacionais para a Educação Profissional Técnica de Nível Médio. Diário Oficial da União. Brasília/DF. Disponível em: < http://www.abmes.org.br/public/index.php/ legislacoes/detalhe/1288/resolucao-cne-ceb-n-6>. Acesso em: 26 mai. 2020.

BRASIL. Lei no 13.415, de 16 de fevereiro de 2017. Estabelece as diretrizes e bases da educação nacional. Diário Oficial da União. Brasília/DF. Disponível em: <http://www.planalto.gov.br/ccivil_03/_ato2015-2018/2017/lei/l13415.htm>. Acesso em: 26 mai. 2020.

BRASIL. Portaria № 343, de 17 de março de 2020. Dispõe sobre a substituição das aulas presenciais por aulas em meios digitais enquanto durar a situação de pandemia do Novo Coronavírus - COVID-19. D.O.U. 18/03/2020. Disponível em: $<$ http://www.in.gov.br/en/web/dou/-/portaria-n-343-de-17-de-marco-de-2020248564376>. Acesso em: 24 mai. 2020.

CARDOSO, Phillipe Valente et al. A importância da análise espacial para tomada de decisão: um olhar sobre a pandemia de COVID-19. Revista Tamoios, v.16, n.1, Especial COVID-19, p.125-137, mai. 2020.

CONIF. FDE. Diretrizes indutoras para a oferta de cursos técnicos integrados ao Ensino Médio na Rede Federal de Educação Profissional, Científica e Tecnológica. 2018. Disponível em: < https://www.ifsc.edu.br/documents/38101/ 1079513/Diretrizes+EMI+-+Reditec2018.pdf/0cd97af4-bad5-b347-4869-

7293ac87eb69 >. Acesso em: 4 nov. 2019.

DOS SANTOS, Carlos Alberto. Desafios para a interdisciplinaridade no ensino das ciências da natureza. Revista Thema, v.15, n.2, p.363-370, 2018.

FIGUEIREDO, Nébia Maria Almeida de. Método e metodologia na pesquisa científica. 2. ed. São Caetano do Sul/SP: Editora Yendis, 2007.

FRANCO, Amanda Gonçalves et al. Máscaras cirúrgicas em tempos de coronavírus. InterAmerican Journal of Medicine and Health, v.3, p.e202003003(1-2), 2020. 
GOOGLE CLASSROOM. Google sala de aula. Disponível em: <https://classroom. google.com>. Acesso em: 31 mai. 2020.

IFNMG, Instituto Federal de Educação, Ciência e Tecnologia do Norte de Minas Gerais, 2017. Projeto pedagógico de curso. Disponível em: <http://documento.ifnmg. edu.br/action.php?kt_path_info=ktcore.actions.document.view\&fDocumentld $=22345$ > . Acesso em: 10 nov. 2018 .

IFNMG, campus Diamantina. Nota Técnica NUPED 01 - Orientações Pedagógicas para o retorno às aulas no contexto da Pandemia da COVID-19. 2020.

Disponível em: <https://www.ifnmg.edu.br/mais-noticias-diamantina/558-diamantinanoticias-2020/24283-nota-tecnica-01-orientacoes-pedagogicas-para-o-retorno-asaulas-no-contexto-da-pandemia-da-covid-19 >. Acesso em: 17 jun. 2020.

IFNMG, Reitoria. Portaria - Reitor $n^{\circ} 221 / 2020$, de 05 de junho de 2020. Aprova, ad referendum, o Plano de Trabalho para a oferta de Unidades Curriculares, de forma remota, previstas no Núcleo Integrador. Disponível em: < $\underline{\mathrm{http}} / /$ documento.ifnmg.edu.br/action.php?kt_path info=ktcore.actions.document. view\&fDocumentld=37703 > . Acesso em: 28 jul. 2020.

KERSKI, Joseph J. The implementation and effectiveness of geographic information systems technology and methods in secondary education. Journal of Geography, v.102, n.3, p.128-137, 2003.

KUHN, T. S. A estrutura das revoluções científicas. (Tradução: Beatriz Vianna Boeira e Nelson Boeira). 5. ed. São Paulo: Perspectiva, Coleção Debates, 1998.

LAVAQUI, Vanderlei; BATISTA, Irinéa de Lourdes. Interdisciplinaridade em ensino de ciências e de matemática no ensino médio. Ciência \& Educação, v.13, n.3, p.399420, 2007.

QGIS._Descubra o QGIS. Disponível em: < https://www.qgis.org/pt_BR/site/about/ index.html>. Acesso em: 29 jun. 2020.

LOUREIRO, Luiz Francisco et al. Interdisciplinaridade: uma proposta epistemológica para a ciência pós-moderna. InterSciencePlace, v.14, n.4, p.127-147, 2019.

OLIVEIRA, Adriana Cristina de; LUCAS, Thabata Coaglio; IQUIAPAZA, Robert Aldo. O que a pandemia da COVID-19 tem nos ensinado sobre adoção de medidas de precaução?

Texto \& Contexto-Enfermagem, v.29, p.e20200106(1-15), mai. 2020.

PAINEL CORONAVÍRUS. Painel de casos de doença pelo coronavírus 2019

(COVID-19) no Brasil pelo Ministério da Saúde. 2020. Disponível em:

<https://covid.saude.gov.br/>. Acesso em: 10 jun. 2020.

RAMOS, Marise Nogueira. A contextualização no currículo de ensino médio: a necessidade da crítica na construção do saber científico. Rev. Ensino Médio, v.1, n.3, p. 9-12, 2003.

RAMOS, Marise. Concepção do ensino médio integrado. Texto apresentado em seminário promovido pela Secretaria de Educação do Estado do Pará nos dias, v.8, 


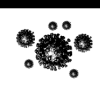

\begin{tabular}{l|l|l} 
V.18 & Especial 2020
\end{tabular}

Edição Especial COVID-19

2008. Disponível em: <http://forumeja.org.br/go/sites/forumeja.org.br.go/files/ concepcao_do_ensino_medio_integrado5.pdf>. Acesso em: 16 out. 2019.

RICHARDSON, Roberto Jarry; DE SOUSA PERES, José Augusto. Pesquisa social: métodos e técnicas. 3. ed. São Paulo: Atlas, 1999.

SANTOMÉ, Jurjo Torres. Globalização e interdisciplinaridade: o currículo integrado. 1. ed. Porto Alegre: Artes Médicas, 1998.

TORI, Romero. Tecnologia e metodologia para uma educação sem distância. EmRede Revista de Educação a Distância, v.2, n.2, p.44-55, 2015.

UNIVERSITY OF CALIFORNIA DAVIS (2020). Disponível em: < https://bio.libretexts.org/ Courses/University of California_Davis/BIS_2A\%3A_Introductory_\%20Biology_(Easlon)/ Readings/15.1\%3A_\%20Membranes>. Acesso em: 27 jul. 2020. 